\title{
CATARACT AS A COMPLICATION OF SEVERE MICROBIAL KERATITIS
}

\author{
R. LOTTI ${ }^{1,2}$ and J. K. G. DART ${ }^{1}$ \\ Genoa and London
}

\section{SUMMARY}

Complicated cataract results from local ocular disease; we report five cases that followed severe anterior segment infection. Three patients had Pseudomonas keratitis and two Acanthamoeba keratitis. All patients had severe keratitis and iridocyclitis. Mature cataracts developed after a mean of $\mathbf{5 . 5}$ months from the onset.

Cataract formation with severe keratitis may be attributable to bacterial toxins, iridocyclitis and treatment toxicity. All these factors may cause cataract by interference with lens metabolism. One of our cases had no steroid treatment; the remaining four had between 7.7 and $28.14 \mathrm{mg}$ of topical steroid (256-938 drops of Dexamethasone $0.1 \%$ ).

Cataract formation may result from severe microbial keratitis alone but is probably enhanced by concurrent treatment with high doses of topical steroid. The potential for cataract formation must be considered when managing microbial keratitis with the use of steroids and when planning surgical rehabilitation of the anterior segment.

The term complicated cataract refers to the lens changes which arise in the course of ocular disease. ${ }^{1}$ Many conditions give rise to complicated cataract: inflammatory diseases including keratitis, scleritis and chronic uveitis, degenerative conditions such as longstanding retinal detachment, retinitis pigmentosa and high myopia, ${ }^{2-3}$ other conditions such as choroidal vascular diseases, absolute glaucoma and ocular surgery, especially glaucoma filtering procedures and retinal detachment surgery. ${ }^{4}$

We report five cases that developed complicated cataract after severe anterior segment infection. All patients attended the Corneal and External Diseases Clinic at Moorfields Eye Hospital. Two patients used extended

'The Corneal and External disease Service, Moorfields Eye Hospital, City Road, London EC1V 2PD.

${ }^{2}$ University Eye Clinic (Director Professor M. Zingirian), San Martino, Vle Benedetto XV, 5, 16132 Genova, Italy.

Correspondence to: J. K. G. Dart, DM, FRCS, FCOphth, Moorfields Eye Hospital, City Road, London EC1V 2PD. wear soft contact lenses. The remaining patients had no identifiable local or systemic predisposing factors.

This retrospective review analyses the possible causes of cataract formation in our patients, with particular regard to the cataractogenic effect of topical steroids. Severe keratitis has a prolonged course and its medical treatment requires high doses of antibiotics. High doses of topical steroids are also often used. Our study was carried out to establish risk factors for the development of cataract in patients with severe microbial keratitis and management guidelines for them.

\section{CASE REPORTS}

Case notes were reviewed. All of the patients treated with steroids used Moorfields Eye Hospital Pharmacy preparations which provide a drop volume of 30 microlitres. Topical steroid dosages were calculated assuming that one 30 microlitre drop was delivered at each application.

\section{Case 1}

A 43-year-old lady developed a Pseudomonas corneal ulcer, in November 1990, after one month of continuous contact lens wear. The keratitis resolved after two months of treatment with $\mathrm{G}$. Tobramycin resulting in a central thin scar with superficial limbal vessels. She was referred to Moorfields Eye Hospital after one month of this treatment. The visual acuity was 6/36. She was maintained on G. Tobramycin $0.3 \%$ for a further two months. She had no treatment with topical or systemic steroid. Five months after onset of the keratitis her vision rapidly deteriorated to counting fingers. On examination a mature cataract was found. She underwent a penetrating keratoplasty with extracapsular cataract extraction and lens implant. Now her vision is $6 / 9$.

\section{Case 2}

A 59-year-old lady had a first episode of Pseudomonas corneal ulcer on September 9, 1990. She improved on G. Gentamicin forte $1.5 \%$, G. Framycetin $0.3 \%$ and G. Neo- 
mycin two hourly. She was started on G. Prednisolone $0.3 \%$ after one week. Three weeks later she had a new episode of inflammation with a large epithelial defect and hypopyon. One week later she was referred to Moorfields Eye Hospital. Her keratitis resolved after treatment with G. Gentamicin forte $1.5 \%$ hourly for three days reducing to four times a day for 28 days, $G$. Framycetin four times a day for 28 days, G. Ceftazidime 5\% six times a day for three days, G. Miconazole $1 \%$ hourly for three days, G. Cefuroxime hourly for five days, G. Vancomycin $5 \%$ hourly for 13 days, G. Ticarcillin $1 \%$ hourly four times a day for 10 days reducing to four times a day for 42 days, $\mathrm{G}$. Dexamethasone $0.1 \%$ six times a day for 30 days reducing to three times a day for 14 days and G. Prednisolone $0.3 \%$ three times a day for 44 days reducing to once a day for 14 days.

Three months after the keratitis onset a mature cataract was identified behind a dense corneal opacity and a cyclitic membrane. Before developing cataract she was treated with G. Dexamethasone $0.1 \% 180$ drops equivalent to $5.4 \mathrm{mg}$, G. Prednisolone $0.3 \% 180$ drops equivalent to $8.8 \mathrm{mg}$. Currently her visual acuity is counting fingers and she is waiting for a combined left cataract extraction and penetrating keratoplasty. In the fellow eye the lens is clear.

\section{Case 3}

A 43-year-old lady had an episode of severe Acanthamoeba stromal keratitis and anterior uveitis at the end of December 1989. There was intense ciliary injection, stromal infiltration throughout the cornea with a ring abscess and hypopyon. She was treated with G. Brolene hourly for 16 days reducing to twice a day for 137 days, G. Neomycin hourly for 16 days reducing to four times a day for 60 days, G. Clotrimazole $1 \%$ four times a day for 76 days, G. Paromomycin six times a day for 300 days, G. Polyhexamethylenebiguanide $0.02 \%$ hourly for 90 days reducing to six times a day for 30 days, G. Prednisolone $0.3 \%$ four times a day for 16 days, G. Prednisolone $1 \%$ hourly for 30 days reducing to four times a day for 16 days, $\mathrm{G}$. Dexamethasone $0.1 \%$ two hourly for eight days reducing to twice a day for 90 days. Throughout this period she had recurrent episodes of inflammation with keratic precipitates, anterior uveitis and retrocorneal membrane formation associated with epithelial defects.

Ten months later we first noticed a posterior subcapsular cataract. Before developing cataract she was treated with G. Dexamethasone $0.1 \% 844$ drops equivalent to $25.35 \mathrm{mg}$, G. Prednisolone $0.1 \% 40$ drops equivalent to $1.2 \mathrm{mg}$, G. Prednisolone $0.3 \% 64$ drops equivalent to $3.8 \mathrm{mg}$.

The keratitis failed to respond to medical treatment and eleven months from onset she underwent a penetrating keratoplasty with extracapsular cataract extraction and lens implant. At the time of surgery there was a dense inflammatory membrane through the anterior chamber, the iris was adherent to the central abscess with a dense cataract and posterior synechiae. Currently her condition is stable with a corrected visual acuity of 6/9.

\section{Case 4}

A 28 year-old lady had an episode of Pseudomonas corneal abscess with a large epithelial defect and hypopyon on May 3, 1991 after a week of continuous lens wear. She was referred to Moorfields Eye Hospital after a further week. Her keratitis resolved after treatment with G. Cefuroxime hourly for five days, G. Gentamicin hourly for five days reducing to two hourly for five days and Gentamicin ointment nocte for 62 days, G. Ticarcillin hourly for 40 days reducing to four times a day for 27 days, Ciprofloxacin iv. $500 \mathrm{mg}$ twice a day for 11 days, G. Dexamethasone $0.1 \%$ two hourly for seven days reducing to once a day for 55 days.

Three months after the onset of keratitis a mature cataract was identified in the presence of an opaque and vascularised cornea. Before developing cataract she was treated with Dexamethasone $0.1 \% 256$ drops equivalent to $7.7 \mathrm{mg}$. Currently her condition is stable and visual acuity hand movements. She is now waiting for a combined penetrating keratoplasty, with tissue matched material, and extracapsular cataract extraction with intraocular lens implant.

\section{Case 5}

A 45 year-old lady had an episode of Acanthamoeba keratitis with a dense ring abscess and hypopyon without epithelial defect on February 13, 1991. The visual acuity was hand movements. The keratitis resolved after treatment with G. Brolene hourly for 30 days reducing to twice a day for another 30 days, G. Clotrimazole six times a day for 7 days, G. Neomycin hourly for 20 days, G. Polyhexamethylenebiguanide six times a day for 167 days reducing to four times a day for 12 days, G. Dexamethasone $0.1 \%$ eight times a day for 276 days reducing to four times a day for 28 days and G. Prednisolone $0.3 \%$ four times a day for 12 days.

Seven months after the keratitis onset a posterior subcapsular cataract was identified behind a central corneal opacity. Before developing cataract she was treated with G. Dexamethasone $0.1 \% \quad 938$ drops equivalent to $28.14 \mathrm{mg}$, G. Prednisolone $0.3 \% 56$ drops equivalent to $1.68 \mathrm{mg}$. Currently her condition is stable and visual acuity hand movements. She is now waiting for a combined penetrating keratoplasty and extraocular cataract extraction with intraocular lens implant.

\section{DISCUSSION}

This study reports five cases that developed cataract after severe anterior segment infection. Cataract associated with severe keratitis has been seldom reported: it was first described by Fuchs ${ }^{2}$ as occurring after 'violent suppurative diseases' of the cornea; Samuels ${ }^{5}$ reported, from enucleation specimens, the alterations in the lens that may take place during the active stage of a purulent ulcer of the cornea.

All our five patients developed a mature cataract within an average of 5.5 months from the keratitis onset. They had severe keratitis and anterior uveitis with cells, flare 
and hypopyon. Cataract formation in association with severe keratitis can be attributed to the effect of bacterial toxins, ${ }^{5}$ iridocyclitis and treatment toxicity.

Bacterial toxins, for example those elaborated by Pseudomonas, may diffuse across the anterior chamber. These may cause cataract by direct injury to the lens epithelium, for instance by bacterial proteases which belong to a group of toxins which damage cell membranes, or indirectly by inhibiting protein synthesis. This might occur following exposure to exotoxin A, which traverses the cell membrane and affects protein metabolism with its ADP-ribosylating activity. ${ }^{6}$

Iridocyclitis may have been a factor in our patients who all had cells, flare and hypopyon. Iridocyclitis-induced cataract is frequently preceded by the development of posterior synechiae and a cyclitic membrane. It comes on slowly and in the later stages of a chronic anterior uveitis it results in a mature cataract. ${ }^{1}$ An experimental uveitis model has shown that cataract is precipitated by a decrease in the aqueous $\mathrm{pH}$ which disrupts the epithelial $\mathrm{Na}^{+} / \mathrm{K}^{+}$ ATP'ase pump resulting in an increase in lens permeability. ${ }^{7}$ Active permeability changes into passive permeability with a consequent increase in sodium and water in the lens. A subcapsular cataract develops. ${ }^{8}$ Another experimental uveitis model ${ }^{9}$ has shown a different mechanism of cataract formation by oxidation of lens proteins. A drop in protein sulphydral groups and an increase in the formation of disulphide bonds in the soluble gamma crystallin protein and later in the albuminoid fraction has been reported. Uveitis may result in an exposure of the lens protein sulphydral groups. This may be important in cataract development in the presence of a functioning lens epithelial pump.

Lastly the cataract may be related to treatment toxicity. All of our patients had been treated with high doses of antibiotics, antiacanthamoeba and antifungal agents, but a correlation between these treatments and cataract formation has not, to our knowledge, ever been reported.

With regard to steroid treatment none of our patients had been treated with systemic steroids. The first patient had never had steroid treatment, however the remaining four were on topical steroids, although the fourth had only had a low dose. It appears that a number of factors are operative in eliciting the pathologic consequences of corticosteroids on the lens. ${ }^{10}$ An experimental model has shown that steroids may cause cataract by inhibiting the $\mathrm{Na}^{+} / \mathrm{K}^{+}$ATP' ase pump mechanism ${ }^{11}$ with the same consequences that have already been described for uveitis. Steroid-induced cataract has been also attributed, both in human steroid-induced cataract and in an experimental model, ${ }^{12-13}$ to the development of covalent glucocorticoidlens protein adducts. Glucocorticoids have been shown to react non-enzymatically with the amino group of lysine residues in lens crystallins. This modification induces a conformational change in the lens crystallins which unveils protein sulfhydral groups. These sulfhydral groups are then free to form disulphide bonds which lead to protein aggregation and to high molecular weight aggregates which refract light. ${ }^{14}$ Another experimental model ${ }^{15}$ has shown that topical application of steroids to rabbit eyes for 40 days did not induce cataract but did lower protein thiol and ascorbate levels in the lens. Nishigori et al. ${ }^{16}$ noted that the steroids that raised glucose levels in the lens (glucocorticoids) were the most effective at inducing cataract in developing chick embryos. But their results showed that this type of cataract could not be explained by either glycosylation of protein, accumulation of polyol, or by osmotic change.

Many studies have revealed the asşociation between posterior subcapsular cataract and topical steroid administration ${ }^{17-21}$ but the critical dose of steroids has never been quantified. The best approximation of this dose is given by Donshick $^{22}$ who showed that the development of a posterior subcapsular cataract was significantly related to the total steroid dose administered in patients who had had graft surgery for keratoconus.

The median dose required to produce cataract in 28 out of 86 patients was 765 (198-upper end of dosage not stated) Dexamethasone $0.1 \%$ equivalent units, $22.95 \mathrm{mg}$, for 10.5 months equivalent to the use of G. Dexamethasone $0.1 \%$ four times a day for 27 weeks. With reference to this amount our third and fifth cases received enough drops to develop a cataract. Treatment in the fourth case was at the lower end of this range. It is possible that the graft surgery, in Donshick's study, enhanced the cataractogenic effect of the steroids. Other studies ${ }^{23}$ suggest that some patients may be more susceptible than others to the side effects of steroids. They report a lack of correlation between the dosage and duration of corticosteroid therapy and posterior subcapsular cataract formation. ${ }^{24-25}$ In conclusion, anterior segment infections if severe, may cause cataract formation. The possible causes of cataract in such patients are bacterial toxins, iridocyclitis and steroid treatment. Each of these has a cataractogenic effect in itself which may be potentiated when they are concurrent. High doses of topical steroids have a well established cataractogenic effect. It is important to consider this effect when managing such cases and to use the minimal dose required to control inflammation. Patients, with severe keratitis, should be advised that cataract may complicate the course of their disease. Cataract may be difficult to identify in the presence of dense corneal opacity and posterior synechiae. Careful preoperative examination is needed to avoid overlooking the cataract when planning surgical rehabilitation of the anterior segment.

Key words: Anterior segment infections, Cataract, Iridocyclitis, Topical steroids.

\section{REFERENCES}

1. Duke-Elder S: Diseases of the Lens and Vitreous, Glaucoma and Hypotony. In Duke-Elder S, ed. System Ophthalmology, Vol. 11, St. Louis: C. V. Mosby, 1969, 210-214.

2. Becker O: Pathologie und Therapie des Linsensystems. In Von Graefe A, Saemisch T eds. Hanbuch der gesamten Augenheilkund. Leipzig: W. Engelman 1874-1880, $157-488$.

3. Fuchs E: Leherbuch der Augenheilkunde. Wien, Deuticke F, 1910, 485-488. 
4. Peyman GA, Sanders DR, Goldber MF: The Lens, Cataract and Its Management. In Principle and Practice of Ophthalmology, Vol. 1, W. B. Saunders Co, 1980, 517-518.

5. Samuels B: Lesions in the lens caused by purulent corneal ulcer. Arch Ophthalmol 1942, 343-52.

6. Stephen J and Pietrowski RA: Aspects of Microbiology 2., Bacterial toxins. 2nd ed. Wokingham, England. Van Nostrand Reinhold Co Ltd, 1986, 11-36.

7. Pau $\mathrm{H}$ and Augstein EM: Durch Acidose (Senkung des $\mathrm{Ph}$ ) bedingte Linsenveranderungen. Albrecht von Graefes Archklin exp Ophthal 1977, 202: 223-9.

8. Pau H: The pathogenesis of subcapsularopacities of the lens (permeability cataract). Doc Ophthalmol 1974, 37(1): 47.

9. Testa M, Bocci N, Fiore C, Calabro S. \& Auricchio G: Influence of experimental uveitis on the rabbit lens. Exp Eye Res 1968, 7: 473-80.

10. Urban RC and Cotlier R: Corticosteroid-induced cataracts. Surv Ophthalmol 1986, 31: 102-10.

11. Mayman CI, Miller D, Tijerina ML: In vitro production of steroid cataract in bovine lens: part 2, measurement of sodium-potassium adenosine triphosphatase activity. Acta Ophthalmol 1979, 57: 1107-16.

12. Bucala R, Gallati M, Manabe S, Cotlier E, Cerami A: Glucocorticoid-lens protein adducts in experimentally induced steroid cataracts. Exp Eye Res 1985, 40: 853-63.

13. Manabe S, Bucala R, Cerami A: Nonenzymatic addition of glucocorticoids to the lens proteins in steroid-induced cataract. J Clin Invest 1984, 74: 1803-10.

14. Bucala R, Manabe S, Urban RC Jr, Cerami A: Nonenzymatic modification of lens crystallins by prednisolone induced sulfhydryl oxidation and aggregate formation: in vitro and in vivo studies. Expl Eye Res 1985, 41: 353-64.
15. Costagliola C, Iuliano G, Menzione M, Apponi-Battini G, Auricchio G: Effect of topical glucocorticoid administration on the protein and nonprotein sulfhydryl groups of the rabbit lens. Ophthalmic Res 1987, 19: 351-6.

16. Nishigori H, Lee JW, Yamauchi Y, Maruyama K, Iwatsuru M: Analysis of glucose levels during glucocorticoidinduced cataract formation in chick embryos. Invest Ophthalmol Vis Sci 1987, 28: 168-74.

17. Valerio M: Les dangers de la cortisonotherapie locale prolongee. Bull Mem Soc Fr Ophthalmol 1963, 76: 572-80.

18. Becker B: Cataracts and topical corticosteroids. Am J Ophthalmol 1964, 58: 872-3.

19. Cronin TP: Cataract with topical use of corticosteroids and idoxuridine. Arch ophthalmol 1964, 72: 198-9.

20. Streiff EB: Evolution de l'opacitie cristallinienne par cortisone locale. Ophthalmologica 1964, 147: 143-8.

21. Burde RM and Becker B: Corticosteroid-induced glaucoma and cataract in contact lens wearers. J Am Med Assn 1970, 213: 2075-7.

22. Donshik PC, Cavanaugh HD, Boruchoff SA, Dohlman CH: Posterior subcapsular cataracts induced by topical corticosteroids following keratoplasty for keratoconus. Ann Ophthalmol 1981, 13: 29.

23. Forman AR, Loreto JA, Tina LU: Reversibility of corticosteroid-associated cataracts in children with the nephrotic syndrome. Am J Ophthalmol 1977, 84: 75-8.

24. Skalka HW and Prchal JT: Effect of corticosteroids on cataract formation. Arch Ophthalmol 1980, 98: 1773-7.

25. Fournier C, Milot JA, Clermont MJ, Regan OS: The concept of corticosteroid cataractogenic factor revisited. Can J Ophthalmol 1990, 25: 345-7. 